\title{
Influence of Pressure Conditioning on the Gas Transport Properties of Imidized Polyamic Acid Films
}

\author{
Hisao HaChisuka, Yoshiharu Tsujita, * Akira TAKIZAWA, \\ and Takatoshi KINOSHITA \\ Department of Materials Science and Engineering, \\ Polymeric Materials Course, Nagoya Institute of Technology, \\ Gokiso-cho, Showa-ku, Nagoya 466, Japan
}

(Received June 13, 1989)

\begin{abstract}
The influence of pressure conditioning on the gas transport properties of various imidized polyamic acid [PAA] films was investigated. The variation of sorption and permeation caused by $\mathrm{CO}_{2}$ pressure conditioning was interpreted using dual-mode sorption and partial immobilization models. The sorption amount of $\mathrm{CO}_{2}$ at $25^{\circ} \mathrm{C}$ of unimidized PAA film increased markedly by pressure conditioning above $30 \mathrm{~atm}$ of $\mathrm{CO}_{2}$. It was found that unimidized PAA film was plasticized at $25^{\circ} \mathrm{C}$ at a pressure above $30 \mathrm{~atm}$ of $\mathrm{CO}_{2}$ and the film cooled relatively quickly to liquid $\mathrm{N}_{2}$ temperature and possibly contain a frozen microvoid or free volume between polymer segments. The sorption amount of $\mathrm{CO}_{2}$ of imidized PAA films also increased by pressure conditioning at $60 \mathrm{~atm}$ of $\mathrm{CO}_{2}$. This can be attributed to increase of unrelaxed volume due to pressure conditioning as shown by increase of Langmuir sorption capacity $C_{\mathbf{H}}{ }^{\prime}$. The increase in $C_{\mathrm{H}}{ }^{\prime}$ of pressure conditioned films with low imide content was larger than that with high content. The diffusion coefficients of Henry and Langmuir modes of $\mathrm{CO}_{2}$ for imidized PAA film, $D_{\mathrm{D}}$ and $D_{\mathrm{H}}$, also increased by pressure conditoning. The increase of $D_{\mathrm{H}}$ of each imidized PAA film was more marked than that of $D_{\mathrm{D}}$.

KEY WORDS Sorption / Diffusion / Polyamic Acid / Imidization / $\mathrm{CO}_{2} /$ Plasticization / Pressure Conditioning / Langmuir Sorption Capacity Term /
\end{abstract}

It is well-known that sorption and permeation of gases in glassy polymer films are quite different from those in rubbery polymer films. This difference can be attributed to the fact that glassy polymers have unrelaxed volume or microvoid frozen in nonequilibrium state between segments. In general, the transport properties of glassy polymers have been analyzed on the basis of the dual-mode sorption $^{1,2}$ and partial immobilization models. ${ }^{3}$ We reported that the nonequilibrium state varied by "thermal conditioning", e.g., quenching from above the glass transition temperature $\left(T_{\mathrm{g}}\right)$ or sub- $T_{\mathrm{g}}$ annealing. ${ }^{4-7} \mathrm{It}$ was found that gas transport properties were influenced by nonequilibrium nature. Namely, gas solubility and diffusivity were enhanced by quenching from above $T_{\mathrm{g}}$ and decreased by sub- $T_{\mathrm{g}}$ annealing, reflecting that unrelaxed volume varies by thermal conditioning.

It is expected that the gas transport properties of glassy polymer depend on the nonequilibrium glassy state frozen by cooling to low temperature, e.g., liquid $\mathrm{N}_{2}$ temperature, after glassy polymer film is exposed to high $\mathrm{CO}_{2}$ pressure similar to thermal conditioning. We term such conditioning as "pressure conditioning". Recently, the plasticization of glassy polymers by sorbed gas has been reported, ${ }^{8-17}$ which might decrease an unrelaxed volume in glassy polymer and reduce $T_{\mathrm{g}}$ of glassy polymer-sorbed gas system. ${ }^{12}$ This pro-

\footnotetext{
* To whom all correspondence should be addressed
} 
vides information on the control of permeability of glassy polymers.

In this article we examined the influence of pressure conditioning on the gas transport properties of various imidized polyamic acid [PAA] films with different $T_{\mathrm{g}}$ and rigidity. The variation of sorption and permeation behavior with pressure conditioning is explained using dual-mode sorption and partial immobilization models.

\section{EXPERIMENTAL}

\section{Materials}

The preparation of various imidized PAA films was described in detail in the previous paper. ${ }^{18}$ Various imidized PAA films were pressure conditioned as follows: PAA films of various imide content were exposed to a fixed pressure of $\mathrm{CO}_{2}$ at $25^{\circ} \mathrm{C}$ for $12 \mathrm{~h}$ and cooled relatively quickly to liquid $\mathrm{N}_{2}$ temperature under the pressure. The pressure was reduced at liquid $\mathrm{N}_{2}$ temperature to keep plasticized structure of various imidized PAA films. The cooling rate used here is considered to be slower than the quenching rate but faster than the slow cooling rate studied before. ${ }^{6,7}$ Imide content did not vary by pressure conditioning.

\section{Method}

$T_{\mathrm{g}}$ of various imidized PAA films at atmospheric pressure and at $60 \mathrm{~atm}$ of $\mathrm{CO}_{2}$ was determined using a differential scanning calorimeter (DSC) [SSC-560, Seiko Electronics Co., Ltd.]. The sample pan of a film at $60 \mathrm{~atm}$ of $\mathrm{CO}_{2}$ was prepared as follows: $\mathrm{A}$ film and dry ice were placed in the pressure aluminium pan and then the pan was sealed completely by an aluminium lid. The pressure of $\mathrm{CO}_{2}$ in the sealed pan was considered approximately 60 atm.

The film sealed with a teflon ring was degassed for $24 \mathrm{~h}$ at $10^{-4} \mathrm{mmHg}$ in a permeation apparatus. The permeation measurement was conducted as follows: after evacuation of a down-stream side of the film up to about
$10^{-4} \mathrm{mmHg}$, gas was introduced into the upstream side, and the permeated gas pressure in the down-stream side was monitored using a MKS-Baratron pressure transducer (227AA). The permeability coefficient was evaluated by a steady state gas permeation rate.

Sorption measurement was carried out using a gravimetric sorption apparatus with electromicrobalance Cahn-2000 (Cahn Instruments, Inc.). After sufficiently dring the film at about $10^{-4} \mathrm{mmHg}$, the amount of $\mathrm{CO}_{2}$ gas sorbed on the films under a certain fixed pressure was corrected by subtracting the buoyancy contribution.

The $\mathrm{CO}_{2}$ used in the sorption and permeation measurements was of greater purity than $99.9 \%$ and used without further purification.

\section{RESULTS AND DISCUSSION}

\section{Variation of $T_{\mathrm{g}}$}

Figure 1 shows DSC thermograms of unimidized PAA film (PAA-0, $T_{\mathrm{g}}=155^{\circ} \mathrm{C}$ ) and PAA film with $41 \%$ imide content (PAA-41, $T_{\mathrm{g}}=227^{\circ} \mathrm{C}$ ), and polyimide film (PI $=\mathrm{PAA}-$ $100, T_{\mathrm{g}}=410^{\circ} \mathrm{C}$ ) under $\mathrm{ca} .60 \mathrm{~atm}$ of $\mathrm{CO}_{2} . T_{\mathrm{g}}$ of the film was lowered markedly by plasticization at 60 atm of $\mathrm{CO}_{2}$ as compared with that of unplasticized film. ${ }^{18}$ The $T_{\mathrm{g}}$ of the film at $60 \mathrm{~atm}$ was below $25^{\circ} \mathrm{C}$ and thus the film was plasticized markedly by $\mathrm{CO}_{2}$ and was in a liquid state at $60 \mathrm{~atm}$. The decrease of $T_{\mathrm{g}}$ was depressed with increasing imide content, corresponding to the rigidity of segment. The gas transport properties of various imidized PAA films may vary by pressure conditioning mentioned above.

\section{Sorption Properties}

Figure 2 shows the sorption isotherms for $\mathrm{CO}_{2}$ at $25^{\circ} \mathrm{C}$ of PAA- 0 conditioned at various pressures of $\mathrm{CO}_{2}$. The sorption amount of $\mathrm{CO}_{2}$ was increased markedly by pressure conditioning above $30 \mathrm{~atm}$ of $\mathrm{CO}_{2}$, while it was not by pressure conditioning below ca. $13 \mathrm{~atm}$. 


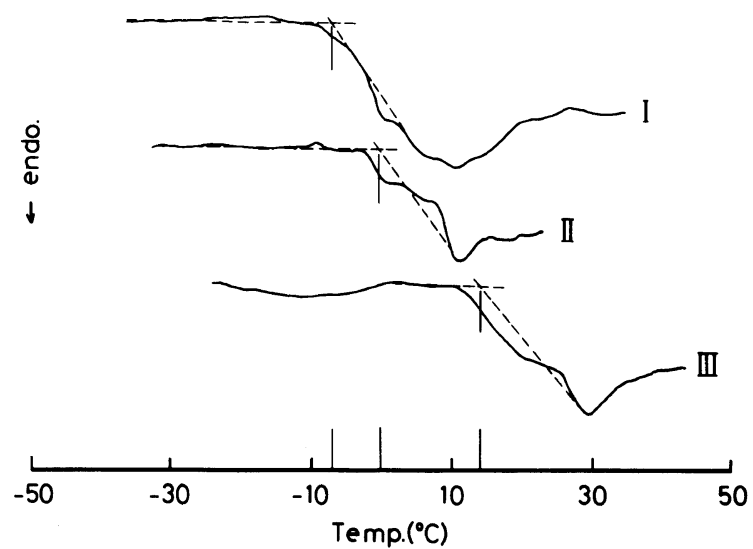

Figure 1. DSC thermograms of PAA-0 (I), PAA-41 (II), and PI (III) under ca. 60 atm of $\mathrm{CO}_{2}$.

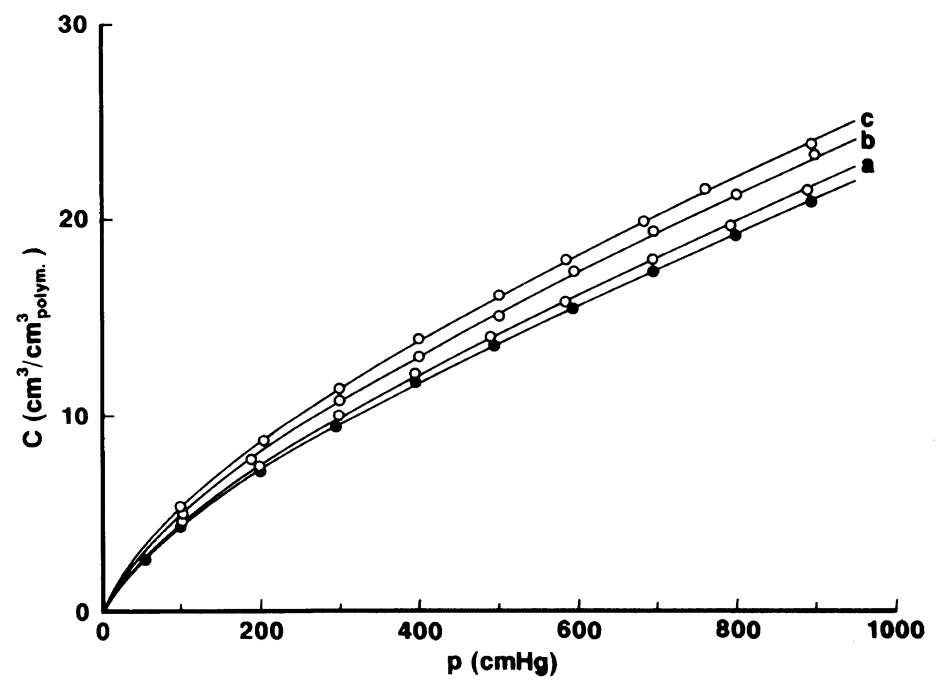

Figure 2. $\mathrm{CO}_{2}$ sorption isotherms at $25^{\circ} \mathrm{C}$ of PAA-0 film conditioned at various pressures of $\mathrm{CO}_{2}$, unconditioned PAA- $0^{18}$, ; (a) PAA- 0 conditioned at $30 \mathrm{~atm}$, (b) PAA- 0 conditioned at $40 \mathrm{~atm}$, and (c) PAA-0 film conditioned at $60 \mathrm{~atm}$.

Isotherms of PAA- 0 conditioned at various pressures were analyzed using the dual-mode sorption model. Each isotherm obtained could be depicted adequately with the model represented by the following equation, ${ }^{1,2}$

$$
C=k_{\mathrm{D}} p+\frac{C_{\mathrm{H}^{\prime}}{ }^{\prime} p p}{1+b p}
$$

where $k_{\mathrm{D}}$ is Henry's law constant, $b$ is the affinity constant of the Langmuir site, $C_{\mathrm{H}}{ }^{\prime}$ is the concentration of penetrant held in "micro- void", and $p$ is the pressure of the penetrant. One can evaluate the dual-mode sorption parameters $\left(k_{\mathrm{D}}, b\right.$, and $\left.C_{\mathrm{H}}{ }^{\prime}\right)$ by curve fitting by the non-linear square method using isotherm data and eq 1. $k_{\mathrm{D}}$ and $b$ obtained were almost independent of pressure conditioning but $C_{\mathrm{H}}{ }^{\prime}$ increased by pressure conditioning. Figure 3 shows the ratio of $C_{\mathbf{H}}{ }^{\prime}$ of PAA- 0 conditioned at various pressures to that of unconditioned PAA-0. The ratio increased with conditioning pressure above $30 \mathrm{~atm}$ of $\mathrm{CO}_{2}$. The plastici- 
zation of PAA-0 caused by sorbed $\mathrm{CO}_{2}$ may occur above $30 \mathrm{~atm}$ of $\mathrm{CO}_{2}$. It was clarified by DSC measurement that $T_{\mathrm{g}}$ of PAA-0 lowered from $155^{\circ} \mathrm{C}$ to $-7.8^{\circ} \mathrm{C}$ by exposure of to $c a$. $60 \mathrm{~atm}$ as shown in Figure 1.

Next, the influence of pressure conditioning at $60 \mathrm{~atm}$ on the sorption properties of imidized PAA films was examined.

Figure 4 shows, as a typical example, the variation of $\mathrm{CO}_{2}$ sorption istherms of PAA-0,

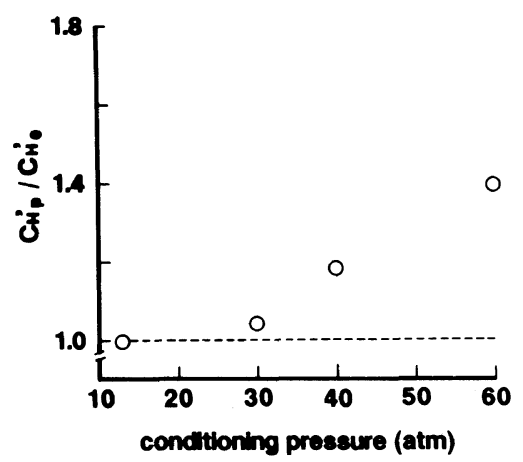

Figure 3. Ratio of $C_{\mathrm{H}}{ }^{\prime}$ of PAA-0 film conditioned at various pressures of $\mathrm{CO}_{2}$ to that of unconditioned film as a function of conditioning pressure.
PAA-41, and PI with pressure conditioning as compared with that of unconditioned films (broken line) shown in the previous paper. ${ }^{6,18}$ Sorption isotherms of conditioned and unconditioned films demonstrate the dual-mode sorption mechanism. The sorption amount of $\mathrm{CO}_{2}$ for each film increased by pressure conditioning. These results are understandable in terms of change in unrelaxed volume or microvoid caused by the pressure conditioning. Therefore, the effect of pressure conditioning on sorption behavior was examined by $C_{\mathrm{H}}{ }^{\prime}$ of dual-mode sorption parameters. The sorption parameters pressure conditioned $(\bigcirc)$ are shown as the function of imide content as compared with unconditioned PAA film $(\mathbf{O})^{18}$ in Figure 5. The change in the $\mathrm{CO}_{2}$ sorption amount in Figure 4 can be represented by variation in $C_{\mathrm{H}}{ }^{\prime}$ of dual-mode sorption parameters. As expected, $C_{\mathrm{H}}{ }^{\prime}$ of PAA film increased by pressure conditioning. However, the other parameters, $k_{\mathrm{D}}$ and $b$, were almost independent of pressure conditioning. This suggests that the variation of $C_{\mathrm{H}}{ }^{\prime}$ contributes

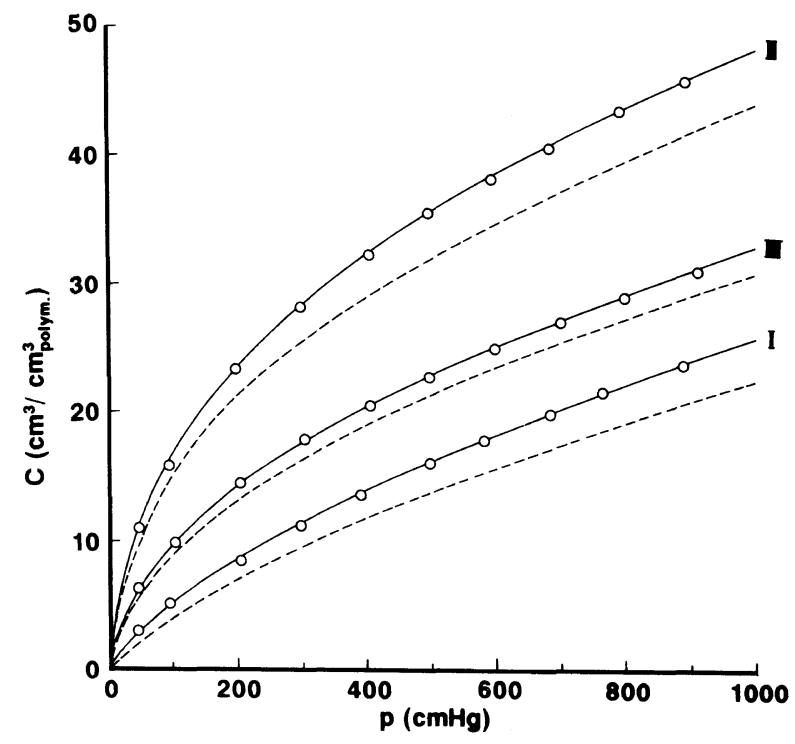

Figure 4. Sorption isotherms at $25^{\circ} \mathrm{C}$ of PAA films having various imide content conditioned at $60 \mathrm{~atm}$ of $\mathrm{CO}_{2}$ : I, PAA-0; II, PAA-41; III, PI. The broken line shows sorption isotherms of unconditioned PAA films ${ }^{18}$ and PI film. ${ }^{6}$ The closed circles are experimental data and solid line corresponds to calculated curve based on the dual-mode sorption model (eq 1). 


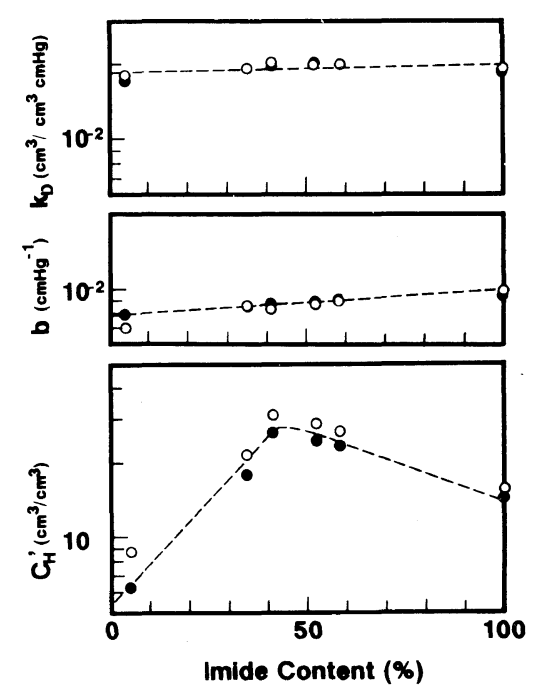

Figure 5. Imide content dependence of dual-mode sorption parameter, $k_{\mathrm{D}}, b$ and $\mathrm{C}_{\mathrm{H}}{ }^{\prime}$ for $\mathrm{CO}_{2}$ of various imidized PAA and PI films before $(O)^{8,18}$ and after $(O)$ pressure conditioning at $60 \mathrm{~atm}$ of $\mathrm{CO}_{2}$.

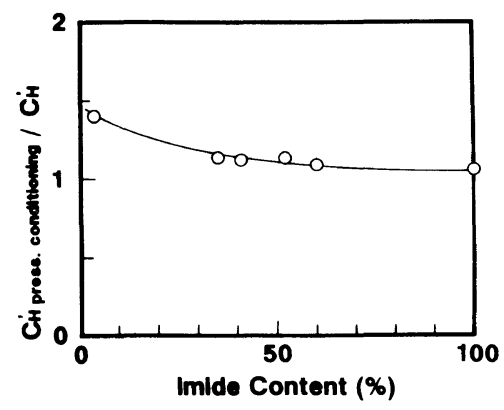

Figure 6. Ratio of $C_{\mathrm{H}^{\prime}}$ of various imidized PAA films obtained by pressure conditioning at $60 \mathrm{~atm}$ to that of unconditioned films.

mainly to the $\mathrm{CO}_{2}$ sorption amount. Here, we discuss the influence of thermal and pressure conditioning. During pressure conditioning, the plasticized structure in liquid state at $25^{\circ} \mathrm{C}$ under $60 \mathrm{~atm}$ of $\mathrm{CO}_{2}$ was glassified by relatively quick cooling to the liquid $\mathrm{N}_{2}$ temperature and the pressure conditioned film possibly contain microvoids, though dependent on cooling rate. Basically the formation mechanism of microvoid is considered to be same as thermal conditioning with which one can control microvoids by quenching from the liquid state above $T_{\mathrm{g}}$. Therefore, the mechanism of variation in $C_{\mathrm{H}}{ }^{\prime}$ by pressure conditioning can be explained as well as that by thermal conditioning. ${ }^{6,7}$

Figure 6 shows the ratio of $C_{\mathrm{H}}{ }^{\prime}$ of pressure conditioned PAA films to that of unconditioned films as a function of imide content. The ratio decreased with increase of imide content. This can be attributed to the fact that the effect of pressure conditioning on PAA films decreases slightly with increase of imide content, reflecting that the reduction of $T_{\mathrm{g}}$ by the plasticization is depressed due to increase of the rigidity of PAA film caused by the imidization.

\section{Permeation Properties}

Figure 7(a) shows, for a typical example, variation of permeability coefficients $(\bar{P})$ of PAA-0, PAA-41, and PI which were pressure conditioned at $60 \mathrm{~atm}$ of $\mathrm{CO}_{2}$. The permeability coefficients of unconditioned films are compared as broken lines in Figure 7 (a). ${ }^{6,18} \bar{P}$ of conditioned and unconditioned films is indicative of characteristic behavior of glassy polymers. $\bar{P}$ of PAA-0, PAA-41, and PI increased by pressure conditioning over the entire pressure region. Figure 7(b) shows the plot of $\bar{P} v s .1 /(1+b p)$ according to the partial immobilization model as shown later. It is obvious that the slope of a straight line of pressure conditioned film becomes more marked compared with that of unconditioned one (broken line) ${ }^{6.18}$ To elucidate the variation of diffusivity by pressure conditioning, two diffusion coefficients $\left(D_{\mathrm{D}}\right.$ and $\left.D_{\mathrm{H}}\right)$ were determined from the slope and intercept shown in Figure 7(b) by applying the partial immobilization model, which is represented by the following equation, ${ }^{3}$

$$
\bar{P}=k_{\mathrm{D}} D_{\mathrm{D}}+\frac{D_{\mathrm{H}} C_{\mathrm{H}}{ }^{\prime} b}{1+b p}
$$

derived assuming individual diffusivity for Henry's law and Langmuir modes, $D_{\mathrm{D}}$ and $D_{\mathrm{H}}$. Figure 8 shows two diffusion coefficients, $D_{\mathrm{D}}$ 

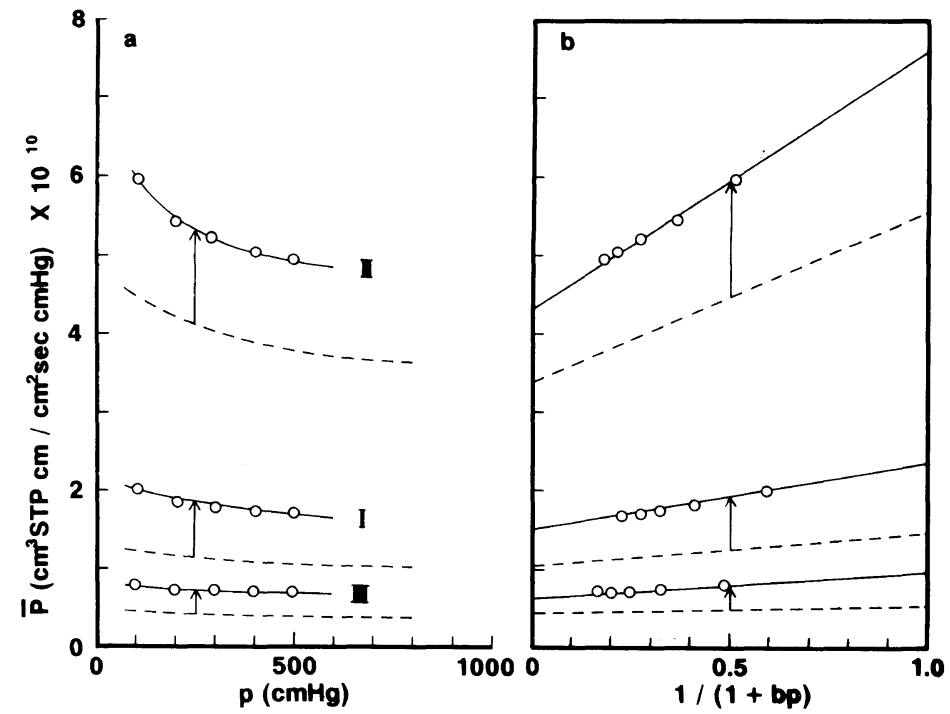

Figure 7. (a) Variation of pressure dependence of permeability coefficients at $25^{\circ} \mathrm{C}$ and (b) permeability coefficients plotted in accordance with the partial immobilization model (eq 2) for $\mathrm{CO}_{2}$ of various imidized PAA films pressure conditioned at 60 atm of $\mathrm{CO}_{2}$; I, PAA-0; II, PAA-41; III, PI. Broken line shows pressure dependence of permeability coefficient of unconditioned PAA films ${ }^{18}$ and PI film. ${ }^{6}$

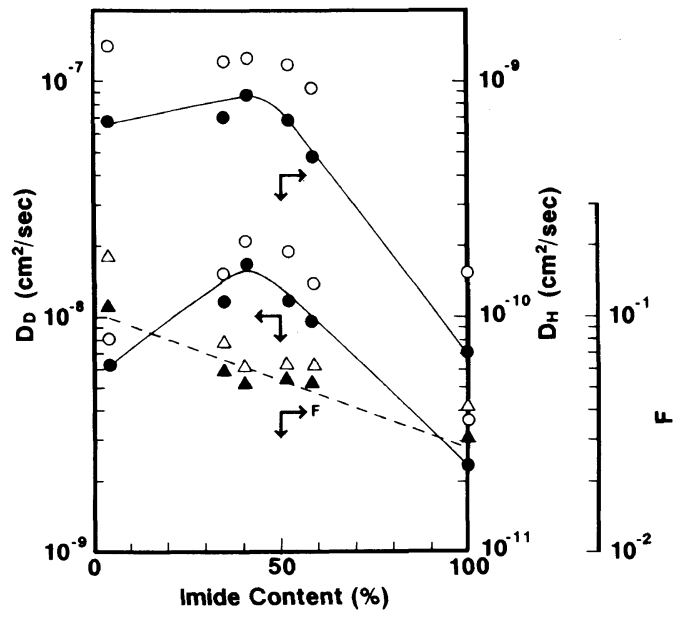

Figure 8. Diffusion coefficients of Henry- $\left(D_{\mathrm{D}}\right)$ and Langmuir- $\left(D_{\mathrm{H}}\right)$ modes and its ratio $F\left(=D_{\mathrm{H}} / D_{\mathrm{D}}\right)$ for $\mathrm{CO}_{2}$ of various imidized PAA and PI films before ()$^{6,18}$ and after $(O)$ pressure conditioning at $60 \mathrm{~atm}$ of $\mathrm{CO}_{2}$ against imide content.

and $D_{\mathrm{H}}$, obtained as compared with that of unconditioned PAA films. ${ }^{18} D_{\mathrm{D}}$ and $D_{\mathrm{H}}$ also increased by pressure conditioning as well as $C_{\mathbf{H}}{ }^{\prime}$. The increase of $D_{\mathbf{H}}$ was larger than that of
$D_{\mathrm{D}}$. This may be attributed to increase of unrelaxed volume caused by pressure conditioning. The variation of diffusivity by the pressure conditioning could be explained as well as that by thermal conditioning as mentioned above.

In conclusion, the sorption amount of $\mathrm{CO}_{2}$ for various imidized PAA films increased markedly by pressure conditioning above 30 atm of $\mathrm{CO}_{2}$. Such variation of sorption can be attributed to increase of unrelaxed volume by pressure conditioning. The ratio of $C_{\mathrm{H}}{ }^{\prime}$ of conditioned PAA film to that of unconditioned one was larger at low imide content than at high content. The $D_{\mathrm{D}}$ and $D_{\mathrm{H}}$ of $\mathrm{CO}_{2}$ for each imidized PAA film also increased by pressure conditioning at $60 \mathrm{~atm}$ of $\mathrm{CO}_{2}$. The increase of $D_{\mathrm{H}}$ caused by pressure conditioning was larger than that of $D_{\mathrm{D}}$. These variations of gas transport properties by pressure conditioning should fundamentally be the same as those by thermal conditioning studied before. The pressure conditioning studied here is an effective method for the control of transport prop- 
erties because the conditioning was carried out at low temperature at which polymers are not degraded.

Acknowledgement. The authors gratefully acknowledge the partial financial support of a Grant-in-Aid for Scientific Research on Priority Areas, New Functionality MaterialsDesign, Preparation and Control, the Ministry of Education, Science, and Culture of Japan (No. 63604546).

\section{REFERENCES}

1. A. S. Micaels, W. R. Vieth, and J. A. Barrie, J. Appl. Phys., 34, 1 (1963).

2. A. S. Micaels, W. R. Vieth, and J. A. Barrie, J. Appl. Phys., 34, 13 (1963).

3. D. R. Paul and W. J. Koros, J. Polym. Sci., Polym. Phys. Ed., 14, 675 (1976).

4. H. Hachisuka, H. Kito, Y. Tsujita, A. Takizawa, and T. Kinoshita, J. Appl. Polym. Sci., 38, 1333 (1988).

5. H. Hachisuka, Y. Tsujita, A. Takizawa, and T. Kinoshita, Polymer, 29, 2050 (1988).
6. H. Hachisuka, Y. Tsujita, A. Takizawa, and T. Kinoshita, J. Polym. Sci., Polym. Phys. Ed., submitted.

7. H. Hachisuka, H. Takizawa, Y. Tsujita, A Takizawa, and T. Kinoshita, Polymer, submitted.

8. Y. Kamiya, K. Mizoguchi, Y. Naito, and T. Hirose, J. Polym. Sci., Polym. Phys. Ed., 24, 535 (1986).

9. Y. Kamiya, K. Mizoguchi, Y. Naito, and T. Hirose, J. Polym. Sci., Polym. Phys. Ed., 24, 1525 (1986).

10. K. Mizoguchi, T. Hirose, Y. Naito, and Y. Kamiya, Polymer, 28, 1298 (1987)

11. Y. Kamiya, T. Hirose, Y. Naito, and K. Mizoguchi, J. Polym. Sci., Polym. Phys. Ed., 26, 159 (1988).

12. J. S. Chiou, J. W. Barlow, and D. R. Paul, J. Appl. Polym. Sci., 30, 2633 (1985)

13. J. S. Chiou, Y. Maeda, and D. R. Paul, J. Appl. Polym. Sci., 30, 4019 (1985)

14. J. S. Chiou and D. R. Paul, J. Appl. Polym. Sci., 32, 2897 (1986).

15. S. Zhou and S. A. Stern, J. Polym. Sci., Polym. Phys. Ed., 27, 205 (1989).

16. R. A. Assink, J. Polym. Sci., Polym. Phys. Ed., 12, 2281 (1974).

17. W. V. Wang, E. J. Kramer, and W. H. Sachse, J. Polym. Sci., Polym. Phys. Ed., 20, 1371 (1982).

18. H. Hachisuka, Y. Tsujita, A. Takizawa, and T. Kinoshita, Polym. J., 21, 417 (1989). 